\title{
Curcuma longa extract nanoemulsion preparation and demonstration of its in vitro activity against Schistosoma mansoni cercariae, schistosomules and adult stages
}

\author{
Nagwa SM Aly', Atef H Husseein ${ }^{1}$, Hanan T Emam², Gehan A Rashed ${ }^{1}$
}

Departments of Medical Parasitology ${ }^{1}$ and Clinical Pharmacology ${ }^{2}$, Benha University, Egypt

\begin{abstract}
Background: Continuous attempts are being made to develop new and more effective drugs for treatment of schistosomiasis. Curcuma longa is a medicinal plant that contains yellow pigments known as curcuminoids (curcumin, bidesmetoxi-curcumin and monodesmetoxi-curcumin), with curcumin as the highest component. The main biological effect depends on curcumin content. Curcumin has low bioavailability and poor-water solubility. Preparation of $C$. longa $(\mathrm{Cl})$ nanoemulsion was attempted to enhance solubility and bioavailability of curcumin.

Objective: The production of $\mathrm{Cl}$ nanoemulsion, and study of its pharmacokinetic properties (namely solubility and intestinal bioavailability) and anti-helminthic effects on Schistosoma mansoni cercariae, schistosomules and adults.

Methodology: $\mathrm{Cl}$ nanoemulsion was prepared from ethanol extract of crude powder of $\mathrm{Cl}$ rhizome. Characterization was done by transmission electron microscope (TEM), testing solubility and intestinal bioavailability. Schistosomicidal effects were performed by in vitro assay.

Results: Cl nanoemulsion showed increased solubility and bioavailability compared to ethanol extract of the tested plant; as well as time and dose dependent schistosomicidal effects on cercariae and $24 \mathrm{~h}$-old schistosomules of $S$. mansoni. In addition, it exhibited an optimal activity against the adult stage with decreased motor activity of the worms.

Conclusion: This study proves that $\mathrm{Cl}$ nanoemulsion has enhanced solubility and bioavailability, as well as schistosomicidal activity.
\end{abstract}

Key Words: Curcuma longa, Nanoparticles, Schistosoma mansoni.

Received: 10 February 2017, Accepted: 8 June 2017.

Corresponding Author: Nagwa S. M. Aly, Tel.: +20-10-1079-4014, E-mail: drnagwashaban@gmail.com.

ISSN: $1687-7942$, Vol. 10, No. $1 \& 2$.

\section{INTRODUCTION}

Human schistosomiasis is a chronic debilitating disease caused by parasites of the genus Schistosoma ${ }^{[1]}$. Schistosomiasis ranks just after malaria in terms of parasiteinduced human morbidity and mortality ${ }^{[2]}$. It is estimated that 779 million people are at risk of schistosomiasis ${ }^{[3]}$. The number of active Schistosoma infections was estimated to be between 391 and 587 million people worldwide ${ }^{[4]}$. Praziquantel and oxamniquine are the drugs available for the treatment of schistosomiasis ${ }^{[5]}$. However, development of resistant strains for both drugs has been reported, leading to schistosomiasis treatment failure that highlighted the importance of developing new and more effective drugs for this disease ${ }^{[6-8]}$. In this context, the past years have been marked by increasing search for anti-parasitic drugs from natural sources. Plants are the major source of biologically active compounds for the development of new treatments ${ }^{[9]}$. In 2013, Abaza $^{[10]}$ reviewed all herbs that were used in treatment of schistosomiasis including Chinese medicine, Carvacrol (essential oil of Origanum vulgare obtained from pepperwort), Myrrh (oleo-gum resin from Commiphoramolmol), artemisinin derivatives isolated from Artemisia annua, curcumin (C. longa), quinine and quinidine (Cinchona officinalis), garlic extract (Allium sativum), black seeds (Nigella sativa) and other several native plants from Brazil.

One of these plants is the rhizome of Curcuma longa, or turmeric (from Zingiberaceae family) which is highly regarded as a universal remedy in herbal medicine, with a wide spectrum of pharmacological activities ${ }^{[11]}$. Turmeric contains $69.4 \%$ carbohydrates, $6.3 \%$ protein, $5.1 \%$ fat, $3.5 \%$ minerals, and $13.1 \%$. moisture. The essential oil $(5.8 \%)$ obtained by steam distillation possesses sesquiterpenes $(53 \%)$, zingiberene (25\%), a-phellandrene $(1 \%)$, sabinene $(0.6 \%)$, cineol $(1 \%)$, and borneol $(0.5 \%)$. Curcumin $(3-$ $4 \%)$ is responsible for the yellow color, and comprises curcumin I (94\%), curcumin II $(6 \%)$ and curcumin III $(0.3 \%)^{[12]}$. Its benefits have been reported against gastrointestinal diseases, hepatic disorder, inflammation, rheumatism, sinusitis, anorexia, cough, anti-cancer, antidiabetic, ant-oxidant, hypolipidemic, anti-microbial, antifertility, anti-venom ${ }^{[11-16]}$. In addition, curcumin possesses 
anti-parasitic activity against $T$. bruce $i^{[17]}, P$. berghei $i^{[18]}$, G. lamblia ${ }^{[19]}$, L. donovani ${ }^{[20]}$, and S. mansoni ${ }^{[21]}$.

However, curcumin is a low water soluble compound, of low bioavailability, which means that its beneficial active compound may not be fully absorbed by the body when it is digested ${ }^{[22]}$. Therefore, improvement of curcumin properties may be beneficial in enhancing its effects. One of the methods is by reducing particle size to a nano size. Nanoemulsions can be prepared by solubilizing the lipophilic bioactive components as the oil phase, and then homogenizing this phase with an aqueous phase containing a water-soluble emulsifier. The small size of droplets in nanoemulsion have different physicochemical and biological properties than in a standard emulsion. Aggregation and separation of particles are better attained when in nanoemulsion form due to the small droplet sizes $^{[23,24]}$. Nanoparticles from curcumin can be prepared by different methods. One of them is a homogenization process, in which a heterogeneous solution classified as nanoemulsion is formed ${ }^{[25]}$. The preparation of $\mathrm{Cl}$ nanoemulsion in our study was attempted to enhance its solubility as well as stability especially for medical application. The droplet size, solubility and penetration of $\mathrm{Cl}$ nanoemulsion were observed and compared with that of an extract curcumin emulsion.

Based on the promising effects of curcumin, the purpose of this work is to evaluate the in vitro effect of $\mathrm{Cl}$ nanoemulsion on $S$. mansoni cercariae, schistosomules and adults.

\section{MATERIALS AND METHODS}

Type of study: Prospective comparative experimental study.

Preparation of $\mathrm{Cl}$ nanoemulsion: $\mathrm{Cl}$ nanoemulsion was prepared from ethanol extract of crude powder of $C$. longa rhizome purchased from the local market. The latter was prepared by mixing $200 \mathrm{~g}$ crude powder of rhizome of tested plant in $800 \mathrm{ml}$ of $98 \%$ ethanol using high speed mixture. Liquid phase was evaporated at room temperature in petri dishes. The resultant powder was preserved in a sterile glass bottle at room temperature till used for preparing the nanoemulsion. Oil water $\mathrm{Cl}$ nanoemulsion was prepared by mixing oil phase of ethanol extract in aqueous phase containing $10 \%(\mathrm{v} / \mathrm{v})$ Tween 80 (based on the oil phase) and maltodextrin (4\% and 10\%) dissolved in phosphate buffer solution (PBS) at $\mathrm{pH} 7$ and stirring using high speed (20000 rpm) magnetic stirrer for at least $15 \mathrm{~min}$ to ensure complete hydration ${ }^{[25]}$. The final product was a stable emulsion containing $20 \%$ ethanol extract of curcumin.

Cl nanoemulsion characterization: Extract particles sizes were measured by using transmission electron microscope (JEM-1200EX, JEOL, Tokyo, Japan), at electron microscope unit, Faculty of Science, Ain Shams University. A drop of the nano-curcumin suspension $(10 \mu \mathrm{L}$; $2 \mathrm{mg} / \mathrm{ml}$ ) was placed on the $3 \mathrm{~mm}$ copper grid and allowed to dry. Solubility of both ethanol extract and nanoemulsion of tested plant were tested against different solvents namely acetone, ethanol, methanol, and cold distilled water. $\mathrm{Cl}$ nanoemulsion particles were mixed with the solvents in the ratio 1:1. The solution was well mixed and allowed to stand for 6 hours before observation to ensure complete dissolving. GIT bioavailabity of different preparations was tested by measuring the extent of their penetration through a closed isolated loop of rabbit's jejunum $10 \mathrm{~cm}$ in length perfused in physiological Tyrod solution at $37^{\circ} \mathrm{C}$ in a $10 \mathrm{ml}$ organ bath for 3 hours. Concentration of absorbed curcumin was measured at maximal absorption of curcumin (530 $\mathrm{nm})$ using a spectrophotometer ${ }^{[26]}$.

\section{Assessment of drug effect on $S$. mansoni stages}

Cercaricidal effect of $\mathbf{C l}$ nanoemulsion: $S$. mansoni (John Bruce Egyptian strain) cercariae were obtained from infected Biomphalaria alexandrina snails obtained from the Schistosome Biological Supply Center (SBSC), Theodore Bilharz Research Institute (TBRI, Imbaba, Giza, Egypt). Cercariae were collected by exposing snails to light for $2 \mathrm{~h}$. The cercariae (from 30 to 40 ) were incubated in 10 $\mathrm{ml}$ dechlorinated tap water. $\mathrm{Cl}$ nanoemulsion was added in final concentrations of $12.5,25,50$ and $100 \mu \mathrm{g} / \mathrm{ml}$, in petri dishes. Untreated cercariae were examined as a control. Cercariae were observed after 5, 30, 60, 90 and $120 \mathrm{~min}$ under a dissecting microscope (Olympus, Tokyo, Japan). The cercariae were considered dead when no movement was observed for at least $1 \mathrm{~min}$ of examination. All the experiments were repeated twice.

Schistosomulicidal effect of $\mathrm{Cl}$ nanoemulsion: Schistosomules were prepared in vitro according to the method of Colley and Wikel ${ }^{[27]}$. Cercariae were subjected to shearing forces created by 10-14 passages through a 22-gauge hypodermic needle. The organisms obtained were concentrated simply by gravity sedimentation on ice. The sediment was re-suspended in RPMI-1640 medium containing $10 \%$ heat-inactivated fetal calf serum, $100 \mathrm{IU} /$ $\mathrm{ml}$ penicillin and $100 \mu \mathrm{g} / \mathrm{ml}$ streptomycin ${ }^{[28]}$. About 20-40 schistosomules were added to each well of sterile tissue culture plates with flat-bottomed wells and incubated overnight in $5 \% \mathrm{CO} 2,100 \%$ humidity, at $37^{\circ} \mathrm{C}$. After $24 \mathrm{~h}$ of incubation, $\mathrm{Cl}$ nanoemulsion was added to the culture medium to give final concentrations of $12.5,25$, 50 , and $100 \mu \mathrm{g} / \mathrm{ml}$. All experiments were performed in duplicates and examined for viability at 24 and $48 \mathrm{~h}$ post treatment. Some wells were maintained without addition of $\mathrm{Cl}$ nanoemulsion as control for non-specific death of schistosomules. The percentage of damaged schistosomules was measured by addition of trypan blue at a final dilution of $0.2 \%$. Dark blue schistosomules that permitted penetration of the dye were considered damaged ${ }^{[28]}$. 
Schistosomicidal effect of Cl nanoemulsion: Swiss albino mice CD-1, weighing 18-22 g each, were obtained from SBSC, kept under environmentally-controlled conditions (temperature $25^{\circ} \mathrm{C}$; humidity $70 \%$; 12-h light and 12-h dark cycle) and acclimatized for one week before infection. The maintenance and care during experimentation of animals was compliant with international guidelines for the human use of laboratory animals. Adult worms were removed from portal and mesenteric veins of infected mice after 90 days $^{[29]}$, sexed and counted ${ }^{[30]}$. Six to ten mature worms including both sexes were cultured per well in 24well plates containing RPMI medium at $37^{\circ} \mathrm{C}$ and $5 \% \mathrm{CO}_{2}$, immediately after animal perfusion to ensure their vitality. $\mathrm{Cl}$ nanoemulsion was added to obtain final concentrations of $12.5,25,50,100 \mu \mathrm{g} / \mathrm{ml}$. Negative control wells contained adults incubated in culture media. All experiments were performed in duplicates and read at 24, 48 and $72 \mathrm{~h}$ post treatment ${ }^{[30]}$. The effect of $\mathrm{Cl}$ nanoemulsion concentrations on $S$. mansoni adult worms were monitored every $24 \mathrm{~h}$ during $96 \mathrm{~h}$ for evaluation of their motor activity. The mortality rate was given a score of $0-3(3=$ normal motility, $2=$ slow motility, $1=$ sluggish motility, $0=$ no motility $)^{[30]}$. The worms were considered dead when no movement was observed for at least 2 min of examination ${ }^{[31]}$.

Statistical analysis: The collected data were analyzed using SPSS version 16 software, data were presented as number and percentage. Goodness of fit test (one way chi square) and $\mathrm{Z}$ tests were used. $P<0.05$ was considered significant.

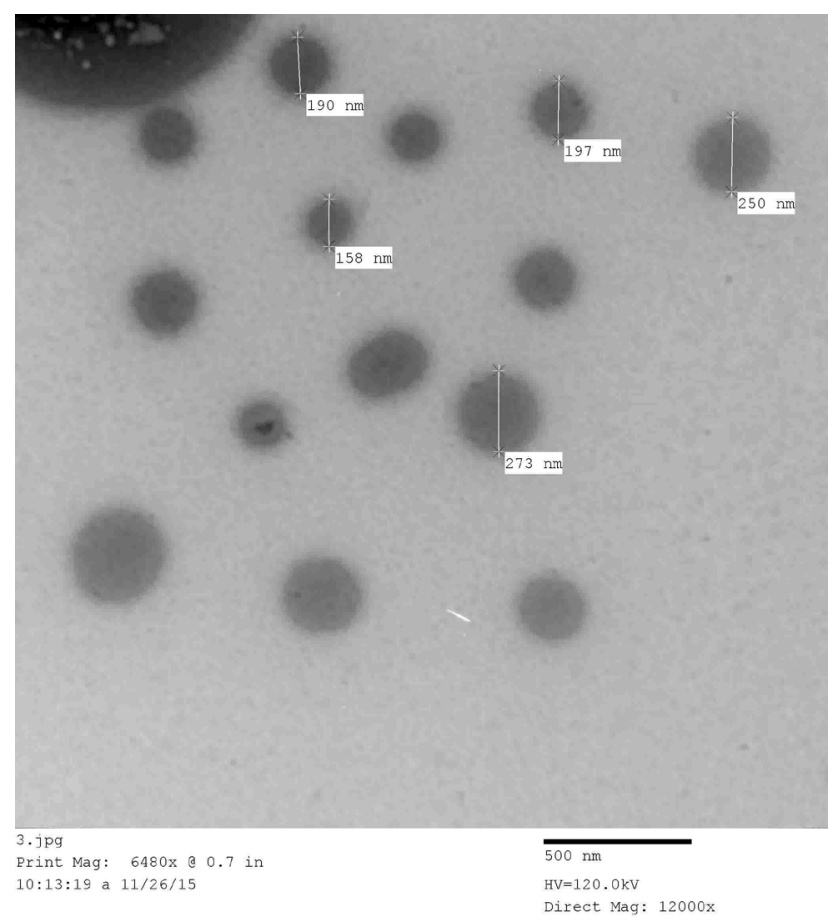

Fig. 1: C. longa extract particles by TEM: Average diameter distribution of extract nanoparticles, $214 \mathrm{~nm}$.size of $214 \mathrm{~nm}$.

\section{RESULTS}

Transmission electron microscopy (TEM) of $\mathrm{Cl}$ nanoemulsion particles showed that the average particles size was $24 \mathrm{~nm} ; \mathrm{Cl}$ extract demonstrated particles with an average size distribution of $214 \mathrm{~nm}$ (Figures 1, 2) $\mathrm{Cl}$ nanoemulsion proved to be highly soluble in water, methanol, ethanol and acetone. The $\mathrm{Cl}$ extract dissolved in methanol, ethanol and acetone, but not water. The in vitro penetration of $\mathrm{Cl}$ nanoemulsion across the membrane cells was $20 \%$, and that of $\mathrm{Cl}$ extract was $13 \%$. $\mathrm{Cl}$ nanoemulsion showed $100 \%$ death of cercariae after $30,60,75 \mathrm{~min}$ for drug concentrations of 100,50 and $25 \mu \mathrm{g} / \mathrm{ml}$, respectively. No cercaricidal effect was noted with drug concentration $12.5 \mu \mathrm{g} / \mathrm{ml}$, after $120 \mathrm{~min}$ incubation.

In vitro schistosomicidal effect of $\mathrm{Cl}$ nanoemulsion on adult worms was statistically significant $(P<0.001)$, according to concentration and incubation period. The effect on their motility was variable after $24 \mathrm{~h}$ of incubation with concentrations of 50, and $100 \mu \mathrm{g}$. After $48 \mathrm{~h}$ of incubation with the same concentration there were variable effects on motility and death of worms. After $96 \mathrm{~h}$ of incubation with $100 \mu \mathrm{g}$ of the nanoemulsion all worms were dead (Table1). There was no statistical significant difference $(P>0.05)$ in its effect on males and females (Figure 3 ). Incubation of $24 \mathrm{~h}$ old schistosomules with different concentrations of nanoemulsion resulted in $100 \%$ mortality after $24 \mathrm{~h}$ incubation at a concentration of $100 \mu \mathrm{g}$. Other concentrations had statistically significant lower effects $(P<0.001)$ (Figure 4$)$.

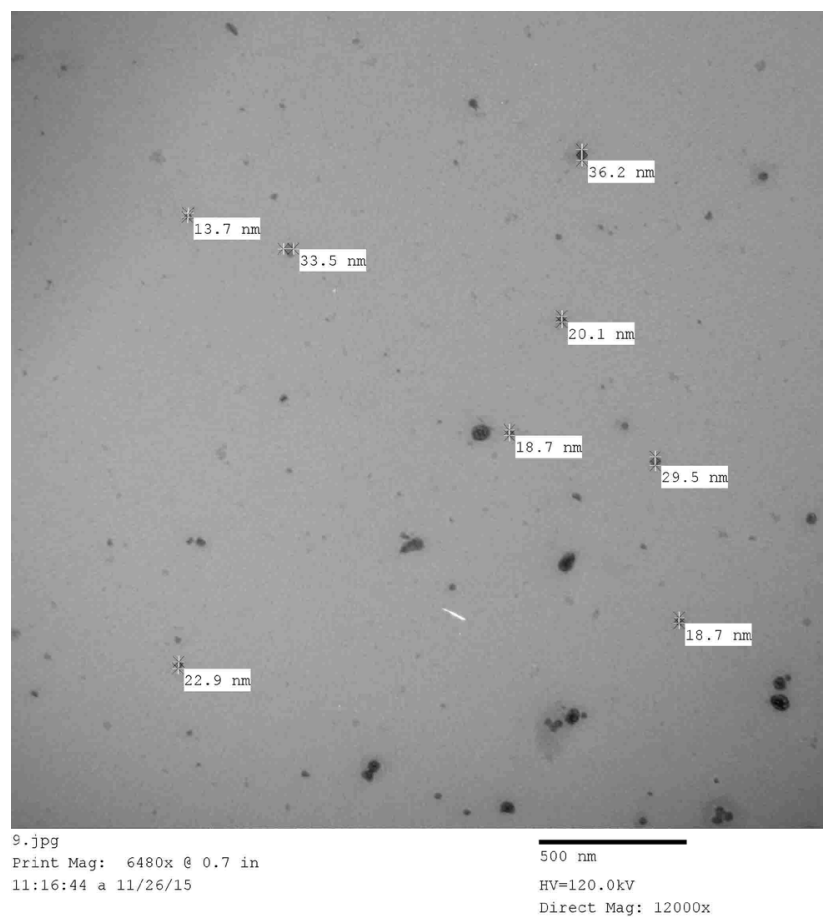

Fig. 2: C. longa nanoemulsion particles by TEM: Average diameter of nanoemulsion particles $24 \mathrm{~nm}$ 
C. longa nanoemulsion effect on $\boldsymbol{S}$. mansoni Aly et al.

Table 1: In vitro schistosomicidal effect of $\mathrm{Cl}$ nanoemulsion on adult worms

\begin{tabular}{|c|c|c|c|c|c|c|}
\hline \multirow{2}{*}{$\begin{array}{l}\text { Tested } \\
\text { group }\end{array}$} & \multirow{2}{*}{$\begin{array}{c}\text { Incubation } \\
\text { period }\end{array}$} & \multirow{2}{*}{$\begin{array}{l}\text { No of } \\
\text { worm }\end{array}$} & \multicolumn{4}{|c|}{ Adult schistosomes activity No. (\%) } \\
\hline & & & $\begin{array}{l}\text { Normal } \\
\text { Score }=3\end{array}$ & $\begin{array}{c}\text { Slow } \\
\text { Score }=2\end{array}$ & $\begin{array}{l}\text { Sluggish } \\
\text { Score }=1\end{array}$ & $\begin{array}{c}\text { Dead } \\
\text { Score }=0\end{array}$ \\
\hline \multirow{4}{*}{ No treatment } & $24 \mathrm{~h}$ & 9 & $9(100 \%)$ & $0(0 \%)$ & $0(0 \%)$ & $0(0 \%)$ \\
\hline & $48 \mathrm{~h}$ & & $9(100 \%)$ & $0(0 \%)$ & $0(0 \%)$ & $0(0 \%)$ \\
\hline & $72 \mathrm{~h}$ & & $9(100 \%)$ & $0(0 \%)$ & $0(0 \%)$ & $0(0 \%)$ \\
\hline & $96 \mathrm{~h}$ & & $9(100 \%)$ & $0(0 \%)$ & $0(0 \%)$ & $0(0 \%)$ \\
\hline \multirow{4}{*}{$100 \mu \mathrm{g}$} & $24 \mathrm{~h}$ & 15 & 0 & $5(33.3 \%)$ & $10(66.7 \%)$ & $0(0 \%)$ \\
\hline & $48 \mathrm{~h}$ & & 0 & $1(6.7 \%)$ & $4(26.7 \%)$ & $3(23.1 \%)$ \\
\hline & $72 \mathrm{~h}$ & & 0 & $0(0 \%)$ & $1(6.7 \%)$ & $14(93.3 \%)$ \\
\hline & $96 \mathrm{~h}$ & & 0 & $0(0 \%)$ & $0(0 \%)$ & $15(100 \%)$ \\
\hline \multirow{4}{*}{$50 \mu \mathrm{g}$} & $24 \mathrm{~h}$ & 13 & $10(76.9 \%)$ & $2(15.4 \%)$ & $1(7.7 \%)$ & $0(0 \%)$ \\
\hline & $48 \mathrm{~h}$ & & $3(23.1 \%)$ & $7(53.8 \%)$ & $2(15.4 \%)$ & $1(7.7 \%)$ \\
\hline & $72 \mathrm{~h}$ & & $2(15.3 \%)$ & $5(38.5 \%)$ & $3(23.1 \%)$ & $3(23.1 \%)$ \\
\hline & $96 \mathrm{~h}$ & & $0(0 \%)$ & $5(38.5 \%)$ & $2(15.4 \%)$ & $6(46.1 \%)$ \\
\hline \multirow{4}{*}{$25 \mu \mathrm{g}$} & $24 \mathrm{~h}$ & 13 & $13(100 \%)$ & $0(0 \%)$ & $0(0 \%)$ & $0(0 \%)$ \\
\hline & $48 \mathrm{~h}$ & & $8(61.5 \%)$ & $2(15.4 \%)$ & $3(23.1 \%)$ & $0(0 \%)$ \\
\hline & $72 \mathrm{~h}$ & & $1(7.7 \%)$ & $8(61.5 \%)$ & $2(15.4 \%)$ & $2(15.4 \%)$ \\
\hline & $96 \mathrm{~h}$ & & $0(0 \%)$ & $5(38.5 \%)$ & $5(38.5 \%)$ & $3(23.0 \%)$ \\
\hline \multirow{4}{*}{$12.5 \mu \mathrm{g}$} & $24 \mathrm{~h}$ & 6 & $6(100 \%)$ & $0(0 \%)$ & $0(0 \%)$ & $0(0 \%)$ \\
\hline & $48 \mathrm{~h}$ & & $6(100 \%)$ & $0(0 \%)$ & $0(0 \%)$ & $0(0 \%)$ \\
\hline & $72 \mathrm{~h}$ & & $0(0 \%)$ & $6(100 \%)$ & $0(0 \%)$ & $0(0 \%)$ \\
\hline & $96 \mathrm{~h}$ & & $0(0 \%)$ & $6(100 \%)$ & $0(0 \%)$ & $0(0 \%)$ \\
\hline \multirow{5}{*}{$\begin{array}{c}\text { Statistical } \\
\text { analysis } \\
P \text { value }\end{array}$} & & $24 \mathrm{~h}: \mathrm{X}^{2}=46.8$ & $0.012(\mathrm{~S})$ & 0.08 (NS) & $0.001(\mathrm{~S})$ & \\
\hline & & $48 \mathrm{~h}: \mathrm{X}^{2}=64.8$ & $0.03(\mathrm{~S})$ & $<0.001(\mathrm{~S})$ & 0.051 & $<0.001(\mathrm{~S})$ \\
\hline & & $72 \mathrm{~h}: \mathrm{X}^{2}=77.07$ & $<0.001(\mathrm{~S})$ & $0.01(\mathrm{~S})$ & 0.23 (NS) & $<0.001(\mathrm{~S})$ \\
\hline & & $96 \mathrm{~h}: \mathrm{X}^{2}=95.4$ & $<0.001(\mathrm{~S})$ & $0.028(\mathrm{~S})$ & $0.015(\mathrm{~S})$ & $<0.001(\mathrm{~S})$ \\
\hline & & $P<\mathbf{0 . 0 0 1}(\mathrm{S})$ & & & & \\
\hline
\end{tabular}

$\mathrm{S}=$ Significant, $\mathrm{NS}=$ Non significant 


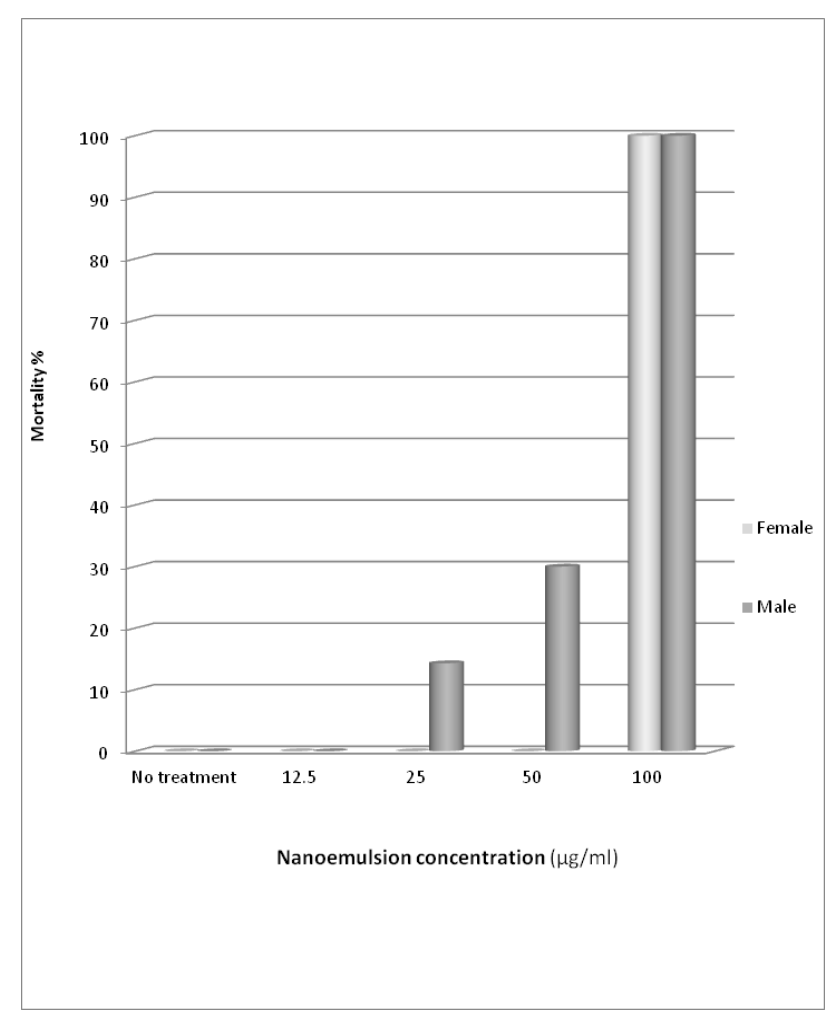

Fig. 3: Schistosomicidal effect of $\mathrm{Cl}$ nanoemulsion on adult males and females $S$. mansoni. No statistical significant difference was detected $(P>0.05)$.

\section{DISCUSSION}

Curcumin is the major constituent in the rhizome of C. longa (Zingiberaceae). It is a naturally occurring compound that exhibits several biological activities ${ }^{[32]}$. Curcumin was active in vitro against schistosomes ${ }^{[21,33]}$, however, no study with curcumin nanoparticles has been tested against Schistosoma species. This study presents the first attempt of preparation and evaluation of nanoparticles from C. longa extract by homogenization method.

In this work, we extracted crude powder of $C$. longa rhizome using ethanol, which possesses predominate polar and minor non polar properties ${ }^{[34]}$. The end product of ethanol extraction of tested plant has a very low yield ( $20 \mathrm{~g}$ out of $1 \mathrm{~kg}$ of crude $C$. longa powder). The method employed in preparation of nanoemulsion improved the hydrophilic properties of the tested plant by transforming water insoluble crude extract into nanoemulsion ${ }^{[25]}$. Tween 80 which is a polyethoxylatedsorbitin acted as emulsifier. It converted particles of tested plant into homogenously dispersed micelles. Tween 80 contains a lipophilic polysorbate group that faces the lipophilic core of curcumin micelle, and a polyoxyethelene hydrophilic group that faces hydrophilic solvents ${ }^{[35]}$. The role of multodextrin in improving solubility of $\mathrm{Cl}$ nanoemulsion is probably attributed to its hygroscopic properties. Magnetic stirring broke $C$. longa particles down into nanoparticles.

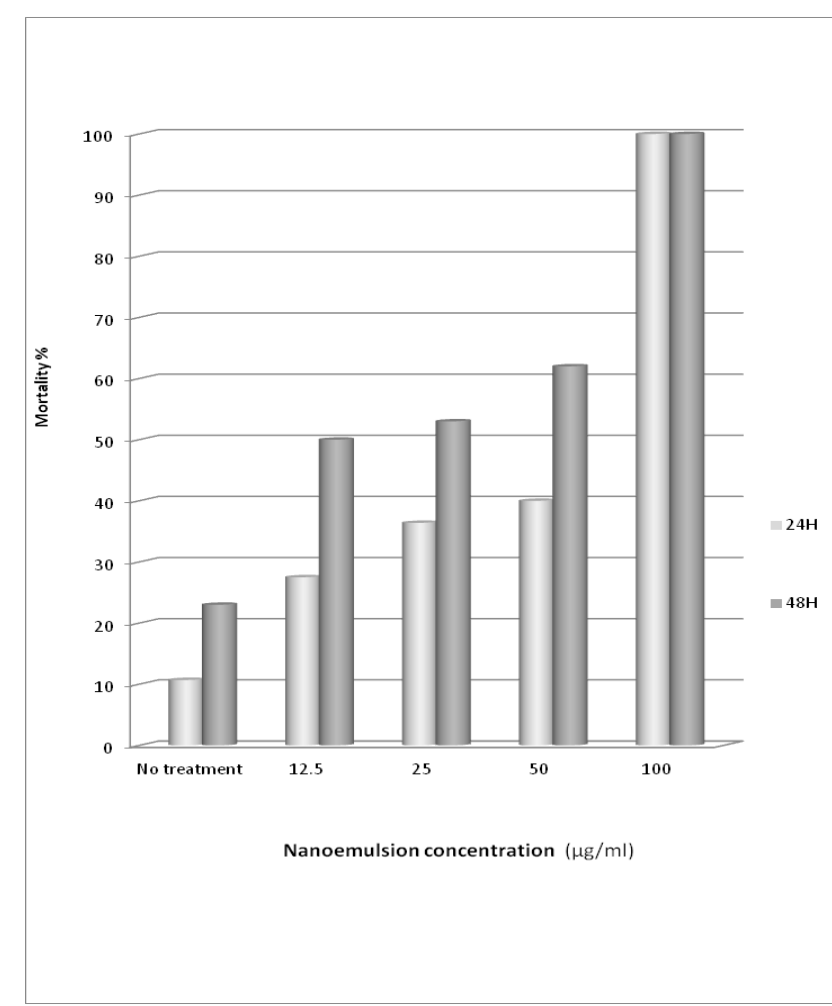

Fig. 4: Effect of $\mathrm{Cl}$ nanoemulsion on 24 hrs-old schistosomules. Data was statistically significant $(P<0.001)$.

The present study revealed marked improvement of GIT bioavailability of $\mathrm{Cl}$ nanoemulsion compared to ethanol extract. This may be attributed to increase solubility of tested product into aqueous media of intestinal lumen. Giacomini and Sugiyama ${ }^{[36]}$ demonstrated that extremely water soluble and fat soluble substances are difficult to pass through a cell membrane. This was attributed to the poor absorption of the former through lipid bilayer of cell membrane, and the latter was attributed to low solubility in aqueous media of biological fluids because drug particles pass biological membranes in soluble form.

Method used in our study for nanoparticles preparation is simple, easy and inexpensive. The formation of spherical particles in the nanosize range was confirmed by transmission electron microscopy, which exhibited an average diameter of $24 \mathrm{~nm}$ (Figure 2) in contrast to 214 $\mathrm{nm}$ of the crude $C$. longa extract (Figure 1). Luz et al. ${ }^{[26]}$ succeeded in producing curcumin nanoparticles with an average size of $108 \mathrm{~nm}$ by incorporating curcumin into poly lacticco-glycolic acid (PLGA) nanospheres using a nanoprecipitation technique. The characters of $\mathrm{Cl}$ nanoparticles are different from crude extract being highly soluble in water, ethanol, methanol and acetone. The crude extract did not dissolve in water but dissolved in ethanol and methanol and acetone. This confirms the experiment done by Jusnita et al. ${ }^{[25]}$ who showed that curcumin dissolves in acetone and ethanol. 
The absorption and bioavailability of the hydrophobic active compound in the body would be enhanced by reducing the size of the molecule. Therefore, rapid penetration of small sized medicine particles occurs and raises the efficiency of the medicine ${ }^{[37]}$. The bioavailability of lipophilic components proved to be greater in nanocurcumins than conventional emulsions ${ }^{[38]}$. Our experiment demonstrated the in vitro penetration of nanocurcumin extract with a molecular diameter size lower than $100 \mathrm{~nm}$ as compared to the crude extract. Penetration of the curcumin extract across the membrane cell was $13.0 \%$ whereas the nanoemulsion penetrated by $20.0 \%$. This indicated a greater penetration of nanocurcumin extract compared to the crude extract, and proved that the smaller molecular size would enhance the penetration across a cell in the body. Another experiment on transport through cells of the skin also showed that application of small size droplets would intensify transport of the active molecule ${ }^{[39]}$. According to $\mathrm{He}$ et al. ${ }^{[40]}$, food proteins stabilize nanoparticles used for delivering water insoluble drugs. This applies to using curcumins in nanoemulsion form as a delivery system to provide a large interfacial surface area for their absorption. In addition, Li and McClements ${ }^{[41]}$ observed that the small droplet size of the lipid phase increases the diffusivity of the cell.

The actual schistosomicidal activity of $\mathrm{Cl}$ nanoemulsion was evaluated in our study. A clear in vitro schistosomicidal effect on cercariae, schistosomules, and adults of S. mansoni was demonstrated. It caused death of $100 \%$ of cercaria, schistosomules, adult male and adult female worms with $100 \mu \mathrm{M}$ at $30 \mathrm{~min}, 24 \mathrm{~h}, 48 \mathrm{~h}$ and $72 \mathrm{~h}$, respectively. In the negative controls (RPMI medium), there were no dead cercariae or adult worms. Schistosomes infect their hosts by aquatic cercariae, which actively invade their host's skin epidermis. Schistosomes survival fully depends on the cercarial invasion success. Many plant extracts were investigated for laboratory anti-cercarial activity. Marston and Hostettman ${ }^{[42]}$ reported seventeen effective compounds against cercariae. Lima et al. ${ }^{[43]}$ reported effectiveness of one single compound. However, these compounds were not active at lower concentrations or at shorter exposure times against cercariae. Chen et al.$^{[33]}$ using pure curcumin reported effective low concentrations against cercariae. In our study, $\mathrm{Cl}$ nanoemulsion showed potential toxicity against cercariae indicating its successful use as a new water soluble cercaricidal agent.

The results showed that both male and female parasites are susceptible to $\mathrm{Cl}$ nanoemulsion. Magalhães et al. ${ }^{[21]}$ showed that curcumin caused $100 \%$ mortality of parasites at a concentration of $50 \mu \mathrm{M}$ after $24 \mathrm{~h}$, and no difference was observed between males and females. In contrast, it has been described in our study as well as in another study ${ }^{[44]}$ that male worms of $S$. mansoni are more susceptible than female worms. On the other hand, De Araújo et $a l^{[5]}$ using nanoemulsion of a new schistosomicidal drug (BphEA) showed that male worms moved slowly at the end of $48 \mathrm{~h}$ whereas all the female worms died. The recorded decreased worm motility produced by $\mathrm{Cl}$ nanoemulsion has been described to be a result of inhibition of smooth muscle proliferation as well as inhibition of histamine induced smooth muscle contrition $^{[45]}$. This is attributed to improvement of penetration of $\mathrm{Cl}$ nanoemulsion particles through parasite tegument, a result of increase passage of hydrophilic pits in schistosomal tegument and enhanced diffusion of nanoparticles. This occurs as a result of the increased solubility of tested product in biological media of the parasite. Claudineide et al..$^{[46]}$ demonstrated that the schistosomal tegument consists of a double layer that encircles a smooth muscle layer and attaches to the suckers. The outer layer is glycocalax that contains hydrophilic pits. The inner one consists of lipid bilayer similar to human plasma membrane. The tegument exerts a regulatory role in passage of nutrients and excretion of lactic acid and metabolic wastes resulting from glycolysis in the parasite. In this context, the tegument represented an important target for anti-helmenthic drugs. In our study the female adult worm which has a thinner tegument and muscle layer showed resistance to the schistosomicidal effect of the tested plant. This contradictory result may be explained by the interaction of female hormonal factors on anti-proliferative and apoptosis promoting effect of tested plant.

In conclusion, curcumin appears as a new potential candidate drug against schistosomiasis. We successfully applied nanoemulsion preparation against different life stages of $S$. mansoni in vitro. Further study is needed to emphasis its effect in vivo. The employment of nanotechnology may offer a safe, effective and cheap treatment.

Author Contribution: NSM Aly conceived the study, wrote the manuscript, and shared $\mathrm{AH}$ Husseein in the study design. Besides, AH Husseein analyzed the data, HT Emam prepared the extract, and all authors performed the experiments and revised the manuscript.

\section{Financial support and sponsorship: Nil.}

Conflicts of interest: There are no conflicts of interest.

\section{REFERENCES}

1. Gryseels B, Polman K, Clerinx J, Luc K. Human schistosomiasis. Lancet 2006; 368(9541): 1106-1118.

2. Colley DG, LoVerde PT, Savioli L. Medical helminthology in the $21^{\text {st }}$ Century. Science 2001; 293(5534): 1437-1438.

3. Steinmann P, Keiser J, Bos R, Tanner M, Utzinger J. Schistosomiasis and water resources development: 
systematic review, meta-analysis, and estimates of people at risk. Lancet Infect Dis 2006; 6(7): 411-425.

4. King $\mathrm{CH}$. Parasites and poverty: the case of schistosomiasis. Acta Trop 2010; 113(2): 95-104.

5. De Araújo SC, De Mattos ACA, Teixeira HF, Coelho PMZ, Nelson DL, De Oliveira MC. Improvement of in vitro efficacy of a novel schistosomicidal drug by incorporation into nanoemulsions. Int J Pharm 2007; 337: 307-315.

6. Cioli D, Pica-Mattoccia L, Archer S. Drug-resistance in schistosomes. Parasitol Today 1993; 9(5): 162-166.

7. Cioli D, Pica-Mattoccia L, Archer S. Anti-schistosomal drugs: past, present and future? Pharmacol Ther 1995; 68(1): $35-85$

8. Pica-Mattoccia L, Dias LCS, Moroni R, Cioli D. Schistosoma mansoni, Genetic complementation analysis shows that 2 independent hycanthoneoxamniquine-resistant strains are mutated in the same gene. Exp Parasito 1993; 77(4): 445-449.

9. de Melo NI, Magalhaes LG, de Carvalho CE, Wakabayashi KAL, Aguiar G, Ramos RC et al. Schistosomicidal activity of the essential oil of Ageratum conyzoidesL (Asteraceae) against adult Schistosoma mansoni worms. Molecule 2011; 16, $762-773$

10. Abaza SM. Treatment of schistosomiasis: From Praziquantel to development of new drug targets: Review article. PUJ 2013; 6(2): 127-148.

11. Nasri H, Sahinfard N, Rafieian M, Rafieian S, Shirzad M, Rafieian-kopaei M. Turmeric: A spice with multifunctional medicinal properties. J Herb Med Pharmacol 2014; 3(1): 5-8.

12. Ammon HP, Wahl MA. Pharmacology of Curcuma longa. Planta Med 1991; 57: 1-7.

13. Huang MT, Lou YR, Ma W, Newmark HL, Reuhl KR, Conney AH. Inhibitory effects of dietary curcumin in stomach, duodenal, and colon carcinogenesis in mice. Cancer Research 1994; 54: 5841-5847.

14. Maheshwari RK, Singh AK, Gaddipati J, Srimal RC. Multiple biological activities of curcumin: a short review. Life Sci 2006; 78(18): 2081-2087.

15. Ammon HP, Anazodo MI, Safayhi H, Dhawan BN, Srimal RC. Curcumin: A potent inhibitor of leukotriene B4 formation in rat peritoneal polymorphonuclear neutrophils (PMNL). Planta Med 1992; 58: 226.
16. Tonnesen H H, Masson M, Loftsson T. Studies of curcumin and curcuminoids. XXVII. Cyclodextrin complexation: Solubility, chemical and photochemical stability. Int J Pharm 2002; 244(1-2): 127-135.

17. Nose M, Koide T, Ogihara Y, Yabu Y, Ohta N, Nose M et al. Trypanocidal effects of curcumin in vitro. Biol Pharm Bull 1998; 21(6): 643-645.

18. Reddy RC, Vatsala PG, Keshamouni VG, Padmanaban G, Rangarajan PN. Curcumin for malaria therapy. Biochem Biophys Res Commun 2005; 326(2): 472-474.

19. Pérez-Arriaga L, Mendoza-Magaña ML, CortésZárate R, Corona-Rivera A, Bobadilla-Morales L, Troyo-Sanromán R et al. Cytotoxic effect of curcumin on Giardia lamblia trophozoites. Acta Trop 2006; 98(2): 152-161.

20. Adapala N, Chan MM. Long-term use of an antiinflammatory, curcumin, suppressed type 1 immunity and exacerbated visceral leishmaniasis in a chronic experimental model. Lab Invest 2008; 88(12): 13291339.

21. Magalhães LG, Machado CB, Morais ER, Moreira EB, Soares CS, da Silva SH et al. In vitro schistosomicidal activity of curcumin against Schistosoma mansoni adult worms. Parasitol Res 2009; 104(5): 1197-1201.

22. Maiti K, Mukherjee K, Gantait A, Saha BP, Mukherjee PK. Curcumin-phospholipid complex: Preparation, therapeutic evaluation and pharmacokinetic study in rats. Int J Pharm 2007; 330(1-2): 155-163.

23. Solans C, Izquierdo P, Nolla J, Azemar N, GarciaCelma MJ. Nano-emulsions. CurrOpin Colloid Interface Sci 2005; 10(3-4), 102-110.

24. Sonneville-Aubrun O, Simonnet J T, L'Alloret F. Nanoemulsions: a new vehicle for skincare products. Adv Colloid Interface Sci 2004; 108: 145-149.

25. Jusnita N, Haditjaroko L, Yusron M, Noor E. Production of nanocurcumin from Curcuma Xanthorriza Roxb. by homogenization. J Biol Agric Health 2014; 4(16): 79- 84 .

26. Luz PP, Magalhães LG, Pereira AC, Cunha WR, Rodrigues V, Marcio L et al. Curcumin-loaded into PLGA nanoparticles preparation and in vitro schistosomicidal activity. Parasitol Res 2012; 110: 593-598.

27. Colley DG, WikelSK.Schistosomamansoni:Simplified method for the production of schistosomules. Exp Parasitol 1974; 35(1): 44-51. 
28. Hussein AH, Kaddag MA, Hamadto HH, El-Hayawan IA, Strickland PT, Abubaker S et al. Schistosoma mansoni: the immune response against cercarial glycocalyx. J Parasitol 1997; 83(3): 424-429.

29. Duvall RH, Dewitt WB. An improved perfusion technique for recovering adult schistosomes from laboratory animals. Am J Trop Med Hyg 1967; 16(4): 483-486.

30. Xiao SH, Mei JY, Jiao PY. The in vitro effect of mefloquine and praziquantel against juvenile and adult Schistosoma japonicum. Parasitol Res 2009; 106(1): 237-246.

31. Manneck T, Haggenmüller Y, Keiser J. Morphological effects and tegmental alterations induced by mefloquine on schistosomula and adult flukes of Schistosoma mansoni. Parasitol 2010; 137(1): 85-98.

32. Allam G. Immunomodulatory effects of curcumin treatment on murine schistosomiasis mansoni. J Immunobiol 2009; 214(8): 712-727.

33. Chen $\mathrm{Y}, \mathrm{Xu} \mathrm{Q}$, Li X, Yang $\mathrm{S}$, Zhu-Ge H. In vitro evaluation of schistosomicidal potential of curcumin against Schistosoma japonicum. J Asian Nat Prod Res 2012; 14(11): 1064-1072.

34. Kosower EM. An introduction to physical organic chemistry. Wiley; New York,1969; p. 293.

35. Chou DK, Krishnamurthy R, Randolph TW, Carpenter JF, Manning MC. Effects of Tween 20 and Tween 80 on the stability of Albutropin during agitation. J Pharm Sci 2005; 94(6): 1368-1381

36. Giacomini K M, Sugiyama Y. Membrane transporters and drug response: Brunton L, Lazo J and Parker K (eds) in: Goodman and Gilman's Pharmacological basis of therapeutics, 2006; $11^{\text {th }}$ edition, McGraw-Hill Professional, USA, pp 41-70.

37. Devarajan V, Ravichandiran V, Masilamani K. Development, characterization, and in vitro evaluation of telmisartan nanoemulsion. IJFST 2013; 1(1): 75-85.
38. Acosta E. Bioavailability of nanoparticles in nutrient and nutraceutical delivery. Curr. Opin. Colloid Interface Sci 2009; 14: 3-15.

39. Fadli A, Nizam AG, Ibrahim A, Nurulnadiah AK, Jiyauddin K, Samer AD et al. Formulation of tetracycline nanoemulsion. WJPR 2015; 4(4): 134-144.

40. He W, Tan Y, Tian Z. Food protein-stabilized nanoemulsions as potential delivery system for poorly water-soluble drugs: preparation, in vitro characterization and pharmacokinetics in rats. Int $\mathrm{J}$ Nanomedicine 2011; 6: 521-533.

41. Li Y, McClements, DJ. New mathematical model for interpreting $\mathrm{pH}-\mathrm{Stat}$ digestion profiles: impact of lipid droplet characteristics on in vitro digestibility. J Agric Food Chem 2010; 58(13): 8085-8092.

42. Marston A, Hostettmann K. Methods in Plant Biochemistry. London Academic Press Limited, London, (Dey PM, Harborne JB, eds) 1991; 6: 153.

43. Lima NM, dos Santos AF, Porfirio Z, Goulart MO, Sant'Ana AE. Toxicity of lapachol and isolapachol and their potassium salts against Biomphalaria glabrata, Schistosoma mansoni cercariae, Artemia salina and Tilapia nilotica. Acta Trop 2002; 83: 43-47.

44. Pica-Mattoccia L, Cioli D. Sex- and stage-related sensitivity of Schistosoma mansoni to in vivo and in vitro praziquantel treatment. Int J Parasitol 2004; 34: $527-533$

45. Nguyen KT, Shaikh N, Shukla KP, Su SH, Eberhart $\mathrm{RC}$, Tang L. Molecular responses of vascular smooth muscle cells and phagocytes to curcumin-eluting bioresorbable stent materials. Biomaterials 2004; 25(23): 5333-5346.

46. Claudineide NF, Rosimeire N, Tarsila F, Vera LG, Silmara MA. Tegument of Schistosoma mansoni as a therapeutic target.In El RidiR (Editor), Parasitic Diseases: Schistosomiasis, Chapter 8. Published by InTechOpen, World's Largest Science, Technology \& Medicine Open Access Book Publisher, 2013. 